\title{
Influence of Pulse Processing of Plant Raw Materials on the Mass Concentration of Crude Extract in Tincturation Technology
}

Sergey Yurievich Smolentsev*, Natalya Olegovna Burova, Faina Ivanovna Gryazina, Nadezhda Ananyevna Kislitsyna, Sergey Ivanovich Okhotnikov, Maria Vasilievna Dolgorukova and Vadim Borisovich Smolentsev

Agrarian Technology Institute, Mari State University, Lenin Square 1, Yoshkar-Ola 424000, Russia

*Corresponding author: Smolentsev SY,Agrarian Technology Institute, Mari State University, Lenin Square 1, Yoshkar-Ola 424000, Russia; E-mail: Smolentsev82@mail.ru Received: May 23, 2016; Accepted: August 23, 2016; Published: August 30, 2016

Copyright: ( 2016 Smolentsev SY et al. This is an open-access article distributed under the terms of the Creative Commons Attribution License, which permits unrestricted use, distribution, and reproduction in any medium, provided the original author and source are credited.

\begin{abstract}
The paper is devoted to the problem of increasing the total concentration of nonvolatile substances in tincture during the extraction process of plant and alcohol-containing raw materials after preliminary pulse processing in the membrane apparatus. Traditionally, biologically active compounds and plant raw materials continue to play a significant role in the modern food production. One of the main goals of modern food technology is the most complete extraction of valuable constituents from raw material and a decrease in their loss during its further processing. The main stage in tincturation is the extraction process, determined by the general laws of mass transfer, the properties of plant tissue, and chemical and physical affinity between the solvent and extracted substance. The article describes the disadvantages of extraction as a method of extracting constituents from plant raw materials and methods to increase the efficiency of this process. The aim of the paper is to research the possibilities for the application of pulse processing of plant raw materials at the preliminary processing stage to increase the yield of extractive substances of the finished product for example of tinctures. The scheme of the developed pulsation apparatus and optimum modes of raw material processing are presented according to the previously conducted research. Infusion technology and control methods for basic quality indicators are taken according to the standard technology. The results of experimental research into the influence of pulse processing on the yield of extractive substances confirm the possibility of using this type of preliminary processing of plant raw materials.
\end{abstract}

Keywords: Pulsation; Plant raw materials; Extraction; Extractive substances; Crude extract

\section{Introduction}

Modern development of the alcohol industry in Russia provides for the rational use of natural plant resources and the development of new types of products using modern technologies.

Tincture is a transparent liquid alcohol or spirit extraction from plant raw materials obtained without heating or removing the extractant.

Ethyl alcohol in various concentrations is used as an extractant depending on the properties of the extracted raw material.

Alcohol effectively extracts useful constituents from raw materials, assuring their long-term preservation. The main method forgetting useful substances for the human body from plantsis extraction. This process is studied in the context of a combination of basic parameters and reagents [1-5].

The method of extraction from plant raw materials is imperfect and has several disadvantages. Due to the low rate of diffusion, the process is carried out for a long time; therefore, the loss of the extractant is possible as a result of evaporation. Also, the mixing process causes difficulties because of the compressed and swollen plant mass on the bottom of the device.

The following methods of dynamic extraction are widely used:

1) circulation of the extractant (formed extract is drained periodically from the bottom of the tincture);

2) fractional (extractant is divided into portions and the raw material is poured over these portions sequentially);
3) centrifugal (it is performed in a filtering centrifuge and the extractant passes through the layer of plant raw materials on the periphery);

4) turbo extraction (the method is based on a vortex mixing the mixture of raw material and extractant by using a turbine stirrer at a speed of 8,000-13,000 rpm;

5) ultrasonic (combination of maceration with the processing of the mixture of raw material and extractant with ultrasound).

These methods significantly reduce the extraction stage (up to several hours or even minutes) in the process of tincturation.

However, preliminary processing of plant material before extraction has not been studied in a proper manner.

There is a processing method for liquid heterogeneous medium, where an oscillation is created in the apparatus. Oscillations are created by vibration or pulsation.

The operation of the pulsation system is to ensure that the pulse generator remotely generates pneumatic pulses of a certain power in the pulsation chamber through a pulse conductor and leads to the oscillation of the suspension [6].

Pulsation systems have been widely studied in the technology of chemical production.

A great contribution to the development of pulsation process is made by Lyashchenko PV, Kutepov AM, Nigmatullin RI, Gubanov AM, Zhikharev AS, Chepura IV, Skorokhodov AG, Reut KV, Bredikhin SA, Efremov VA, Ivanov GI, Ibytov RI, Ivannikova EM, and many other scientists [6]. 
Citation: Smolentsev SY, Burova NO, Gryazina FI, Kislitsyna NA, Okhotnikov SI, et al. Influence of Pulse Processing of Plant Raw Materials on the Mass Concentration of Crude Extract in Tincturation Technology. Biol Med (Aligarh) 8: 353. doi: 10.4172/0974-8369.1000353

Page 2 of 3

\section{Materials and Methods}

The research into the possibility of using pulsation at the stage of preliminary processing of raw material to increase the yield of extractive substances was carried out in the pulsation apparatus developed at the Department of the Technology of Storing and Processing Plant Products in Mari State University (Figure 1). Sea buckthorn berries, ethyl alcohol, potable water, and other raw materials were used according to the requirements of existing GOST.

The pulsation apparatus consists of a hollow glass tube (1), divided into the work zone and the settling zone (stabilizer). The frequency of pulse oscillations is regulated by the converter and transmitted to a pulsator, made in the form of the membrane (2) through the eccentric (4) and the rod (3). The work is carried out from the electric motor through the reducer. Pulsation amplitude is $2 \mathrm{~mm}$ due to the design of the pulsation apparatus.

The extract had been processed with the apparatus for $30 \mathrm{~min}$, and the pulsation frequency was $\mathrm{n}=8-9 \mathrm{~Hz}$ with an oscillation amplitude of $2 \mathrm{~mm}$. These parameters were taken as optimal according to the preliminary testing [7-9].

The typical recipe was taken as the basis for the tincturation, which is presented in Table 1.

Infusion and pouring technologies were taken according to the standard technology.

Before blending, semifinished products were examined for the following parameters: alcohol according to GOST R 51135-2010, mass concentration of crude extract with refractometric method according to GOST R 51135-2010, organoleptic indicators according to GOST R 52522-2006.

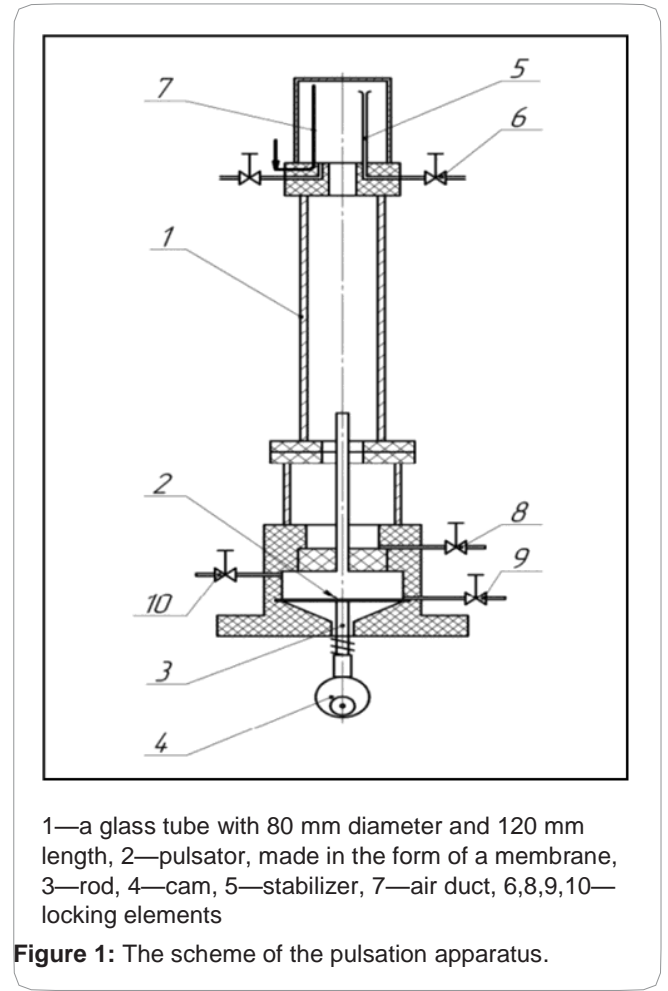

\section{Results and Discussion}

The aim of the paper is to research the possibilities for the application of pulse processing of plant raw materials at the preliminary processing stage to increase the yield of extractive substances by the example of tinctures.

Experimental research was carried out in accordance with the existing standards and techniques to get the primary information in the form of random processes with their subsequent processing on a personal computer with Microsoft Excel.

One of the main indicators influencing the quality of the finished tincture is the indicator of the mass concentration of the crude extracttotal concentration of all dissolved substances.

The results of the determination of the mass concentration of the crude extract of semifinished and finished tincture are presented in Table 2 .

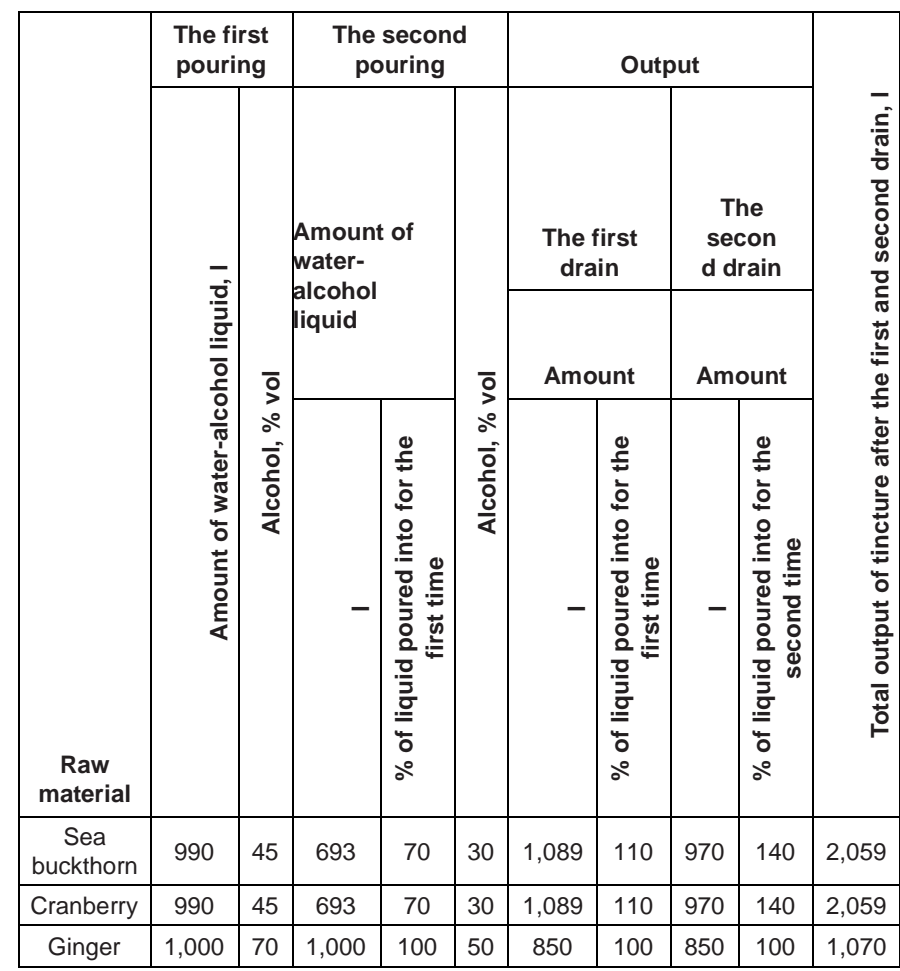

Table 1: The output of tincture from $1,000 \mathrm{~kg}$ of fresh fruit and berries.

\begin{tabular}{|c|c|c|c|c|c|c|}
\hline & \multicolumn{3}{|c|}{ With pulsation } & \multicolumn{3}{|c|}{ Control } \\
\cline { 2 - 8 } Indicators & $\mathbf{1}$ & $\mathbf{2}$ & $\mathbf{3}$ & $\mathbf{1}$ & $\mathbf{2}$ & $\mathbf{3}$ \\
\hline $\begin{array}{c}\text { Mass concentration of the crude } \\
\text { extract after the first drain, g/dm }\end{array}$ & 6.4 & 6.4 & 6.4 & 4.2 & 4.6 & 4.6 \\
\hline $\begin{array}{c}\text { Mass concentration of the crude } \\
\text { extract after the second drain, g/dm }\end{array}$ & 3.6 & 3.6 & 3.6 & 3.8 & 4.0 & 3.8 \\
\hline $\begin{array}{c}\text { Mass concentration of the crude } \\
\text { extract after the first and second } \\
\text { drain, g/dm }\end{array}$ & 5.2 & 5.1 & 5.2 & 4.0 & 3.9 & 3.9 \\
\hline
\end{tabular}

Table 2: The results of the determination of the mass concentration of the crude extract with refractometric method. 
Citation: Smolentsev SY, Burova NO, Gryazina FI, Kislitsyna NA, Okhotnikov SI, et al. Influence of Pulse Processing of Plant Raw Materials on the Mass Concentration of Crude Extract in Tincturation Technology. Biol Med (Aligarh) 8: 353. doi: 10.4172/0974-8369.1000353

Page 3 of 3

Metrological characteristics of the conducted experiment are the convergence of the results when the allowable absolute difference between the two results is no more than $0.7 \mathrm{~g} / \mathrm{dm}^{3}$.

The standard technology of tincturation involves a 6 day ageing of raw material and extractant. The experimental sample prepared with the use of pulse processing and the control sample prepared according to the traditional technology, were subjected to laboratory testing on a daily basis. The mass concentration of the crude extract of the semifinished product was recorded after the first and second drain, and the mass concentration of a finished tincture was recorded after blending.

The results of the experiment show that with pulse processing, mass concentration of the crude extract after the first drain was $6.4 \mathrm{~g} / \mathrm{dm}^{3}$, that is, $2.2 \mathrm{~g} / \mathrm{dm}^{3}$ more than in the control sample.

In addition, the output of extractive substances was more complete, and the mass concentration of the crude extract after the first and second drain was $5.17 \mathrm{~g} / \mathrm{dm}^{3}$ on average, which exceeded the same indicators in the control sample by $31.6 \%$.

Thus, preliminary pulse processing of raw materials gives the opportunity to get a greater amount of extractive substances from plant raw material, thereby improving the quality of the finished product.

Perhaps, the underlying reason for such effect is the phenomenon of uneven increase in the mass transfer in the regime of phase inversion between the gas and liquid phases in porous media at maximum flow rates corresponding to the transition of the gas phase to the dispersion phase and the liquid phase to the solid phase.

\section{Conclusion}

According to the study, the use of preliminary processing of plant raw materials in pulsation apparatus in the mode - the amplitude of pulsation $\mathrm{A}=2 \mathrm{~mm}$, frequency of pulsation $\mathrm{n}=8-9 \mathrm{~Hz}$, duration of processing $\mathrm{t}=30 \mathrm{~min}$ - has a positive effect on the increase in the content of crude extract in the finished product.

The research into the application of the pulsation method for food systems allows us to conclude about its potential. In addition, the method of pulsation is not sufficiently investigated in food systems and serves as the basis for the creation of new food technologies and devices.

\section{References}

1. Zhao D, Li H-B, Xu J-Y, Luo J, Ma LQ (2015) Arsenic extraction and speciation in plants: comparison and development method. Sci Total Environ 523: $138-145$

2. Wang M, Bi W, Huang $X$, Chen Dda $Y$ (2016) Ball mill assisted rapid mechanochemical extraction method for natural products from plants. J Chromatogr A 1449: 8-16.

3. Veggi PC, Cavalcanti RN, Meireles MAA (2014) Production of phenolic-rich extracts from Brazilian plants using supercritical and subcritical fluidextraction: Experimental data and economic evaluation. J Food Eng 131: 96-109.

4. Saini RK, Keum YS (2016) Tocopherols and tocotrienols in plants and their products: a review on methods of extraction, chromatographic separation, and detection. Food Res Int 82: 59-70.

5. Fornari T, Vicente G, Vázquez E, García-Risco MR, Reglero G (2012) Isolation of essential oil from different plants and herbs by supercritical fluid extraction. Chromatogr A 1250:34-48.

6. Karpacheva SM (1980) Fundamentals of the Theory and Calculation of Pulsating Column Reactors. Moscow: Atomizdat.

7. Yunusov SG (2013) Research into the influence of pulse processing on the process of separation of a heterogeneous food medium. Agric Sci Euro North East 1: 69-72.

8. Yunusov SG (2013) The results of the research into the process of separation of food suspension with pulsation apparatus. Vestnik of Kazan State Agric Univ 2: 99-102.

9. Yunusov SG (2013) Research into the influence of pulse processing and temperature on the process of separation of a liquid heterogeneous food medium. Vestnik of Mari State Univ 24-26. 